\title{
A Theory of General Impairment of Gene-Expression Manifesting as Autism
}

\author{
Robin P. Clarke \\ Birmingham, England \\ rpclarke(at)rpcc.info \\ (Received 20 September 1991; received for publication 14 July 1992)
}

Summary--This is the first part of a combined theory of autism and general intelligence (IQ). It is argued that general impairment of gene-expression, produced by a diversity of environmental and genetic causes, is in moderation advantageous in suppressing genetic idiosyncracies. But in excess it will produce a condition involving abnormalities of appearance and behaviour, with a particular relationship to high parental social class and IQ and with particular sex distributions. Character-istics and findings relating to schizophrenia, manic-depressive illness, or neuroses indicate that they cannot reasonably be considered manifestations of excessive general impairment of gene-expression. By contrast, characteristics and findings relating to autism accord very well with this conception. The suggestion is that autism involves primary abnormalities in diverse parts of the brain and in diverse psychological functions. Random binding to DNA may be a substantial mechanism of general impairment of gene-expression. [i.e., would definitely cause impairment, and hence cause autism, but only may be substantially involved (see para. 15)].

It will be argued that the most prominent effect of general impairment of gene-expression is the pro-duction of individual differences in innate general intellectual ability, by variable degrees of suppression of certain characteristics that tend to produce slowing and errors in intellectual processing. But that in excess it causes the autistic syndrome. The full application of the theory to intelligence and its correlates will be presented in a separate paper.

There have been many theories of autism. But there appear to be no other theories of how general impairment of gene-expression would manifest itself.

The present theory differs from other theories of autism in having the following combination of characteristics.

It is founded on an argument from wellestablished biological principles, providing it with a basis in the context of evolution by natural selection. Indeed, several hypotheses that emerged in the course of development of the theory turned out to be already well-established findings, namely the association of reliability of expression with advantageousness, the reemergence of long-suppressed characteristics, and the conservatism and resistance to change of characteristics other than of appearance and behaviour.

It provides an explanation of why such a severely biologically disadvantageous condition is not eliminated by natural selection, and of why it is a relatively common mode of failure of the brain.

It addresses an exceptionally broad range of findings about autism (and IQ). These include the wide diversity of behavioural abnormalities (listed in table 2), including some particularly odd ones, such as the distinctive hand-flapping and posturing, and also the physical stigmata, attractiveness of appearance, special skills, above-average parental IQ and differentially elevated parental social class, the fourfold preponderance of males among the severely autistic, and the tenfold preponderance among the mildly autistic.

Numerous specialist readers have found not one finding to cast doubt on the theory, nor any flaw in the arguments presented here. This was not for want of hostility.

And yet the theory cannot validly be dismissed as untestable, or as equally compatible with any 
conceivable findings. Were such a criticism justified, it would be possible to provide some substantiation by substituting, in place of findings about autism, the findings about other conditions such as schizophrenia, manicdepressive illness, or the like, and then rewriting the pages that follow so as to explain all those findings instead. It will become clear that any such explanations would be not merely speculative but absurd and incredible. For example, why should general impairment of gene-expression manifest as alternating mania and depression? Why should it first appear in adolescence, as does schizophrenia, and why involve remissions and relapses? Why should relapses be specifically triggered by hostility from others? Why should it be ten times more prevalent among Afro-Carribeans born in Britain than among those migrating there, as is schizophrenia? Clearly the charge of untestable explain-all is unwarranted.

The above combination of characteristics is very exceptional in a scientific theory. Publication of the theory should not be further suppressed by facile empty innuendos of "speculativeness" or "untestability", but only by substantiated arguments and evidence that prove able to stand up to rejoinder.

Subsequent to the above words, referees and editors of the British Journal of Psychology, recognising the untenability of all other objections, concurred in the view that the theory made no unforseen predictions (and was thus unworthy of publication even as an article). This is simply not true. For example pages 1920 predict sequences of changes of SES and IQ distribution in reponse to certain environmental factors; page 37 predicts certain EEG findings; page 24 predicts that rigorous investigation will confirm subjective impressions of tendency to intelligent-looking and attractive appearance. But anyway, note that Darwin's theory of natural selection made no unforseen predictions whatsoever. Why is this "criticism" so damning in this case but not at all in Darwin's case?

The scope of the present theory is the whole of the syndrome that includes Kanner's (1943, 1973) syndrome, Asperger's (1944) syndrome, early infantile autism, pervasive developmental disorder, autistic-like individuals, and others who have one or two autistic characteristics. Wing (1988) and Wing and Gould (1979) describe a broad syndrome, the autistic continuum, involving variation in both number and intensity of abnormalities. The present theory is a general theory of that broad phenomenon; it accords with the evidence of diversity of causes and effects, but is not here extended to consideration of details of causal processes in specific cases, because that would be excessively speculative at present.

\section{General Impairment of Gene-Expression}

There now follows a presentation of an argument to the effect that general impairment of gene-expression would, in excess, be expected to give the characteristics of autism. Thereafter the theory is related to empirical findings and to other theories and ideas.

Gene-expression in its most narrow conception is the transcription of genetic material into proteins. In this paper the term is used more broadly to denote all or most of the processes through which genes affect the characteristics of phenotypes. It hardly needs arguing that these gene-expression processes are affected by environmental factors (otherwise, variation, physical or psychological, would be totally genetically determined). And it is equally wellestablished that gene-expression is affected by other genes, such as in interactive effects (epistasis) and that some genetic material, such as regulatory genes, and DNA sequences for initiation and termination of transcription, has effect mainly in enabling or disabling the expression of other (structural) genes. There is evidence that regulatory genes are involved in mammalian brain development (He et al, 1989).

It is here proposed that some of these factors, both environmental and genetic, produce an effect of substantially general and indiscriminate impairment of gene-expression. It appears that this is an idea that has not previously been postulated let alone investigated, yet it seems very unlikely that such general-acting factors do not exist. Gene-expression depends on processes that have many possibilities for malfunction, with many common factors underlying (for example) all transcription from DNA, all being dependent on, for example, supply of nutrients and oxygen, and freedom from interference by viruses.

As for the idea that general impairment of gene-expression can be produced by genes, it will be argued further on that such genes would necessarily be highly advantageous. This makes their prominent existence virtually inevitable 
when set in the context of a second consideration, namely that the random generation of a mechanism that generally impairs geneexpression is very much more probable than the random generation of (say) innate tendencies required for eating or drinking.

One such mechanism of genetically-produced general impairment is described by Watson, Hopkins, Roberts, Steitz, and Weiner (1987). This relates to the fact that regulatory proteins (the products of regulatory genes) not only have a strong affinity for their specific binding sites on DNA, but also have a general though much lower affinity for non-specific (random) DNA sequences; thus there is "part-time" binding to "irrelevant" stretches of the genome. The effect of such random binding is to prevent access by activator molecules and RNA polymerases, thus preventing transcription and gene-expression. Obviously, then, a surplus of regulatory proteins (or pseudo-regulatory proteins) would give the postulated general, indiscriminate impairment of gene-expression, but whether this is the principal or even a major process is not clear at present.

For convenience of exposition, processes and factors that produce general, indiscriminate impairment/suppression of gene-expression will hereinafter be referred to as antiinnatia. Note that it involves both genetic and environmental factors.

The argument that follows proves that antiinnatia must have a quality-controlling effect, eliminating/ suppressing relatively disadvantageous characteristics and tending to leave those that have a history of advantageousness.

(It is contended that the following two statements are self-evidently true.)

In respect of genes producing advantageous effects those producing them reliably will be more consistently selected in by natural selection. By contrast, in respect of genes producing disadvantageous effects those producing them reliably will be more consistently selected out. Hence in respect of advantageous effects reliability will become relatively preponderant whereas in respect of disadvantageous effects reliability will become relatively rare. That is, there will be a positive correlation between advantageousness and reliability of expression. But this is hardly a radical conclusion; it is well known that dominant characteristics tend to be advantageous and recessives disadvantageous (though biologists have failed to discover the reason just presented (Futuyma, 1986, p 211)).

Thus, characteristics having a history of advantageousness will tend to be more reliably expressed, or in other words, less reliably suppressed, that is, will tend to be less affected by antiinnatia.

The implication of this is that antiinnatia has a quality-controlling effect, tending to suppress recently acquired idiosyncracies (which tend to be disadvantageous) and leaving those characteristics that have a relatively substantial history of advantageousness.

It should be noted that the idiosyncracies involved can be both (1) idiosyncracies within a species, i.e., characteristics uncommon in the species in question; and (2) idiosyncracies between species, i.e., characteristics of a species that are uncommon among related species (e.g., language among mammals). Furthermore, antiinnatia has no magic means of discerning advantageousness, present or past, but rather there is the tendency, for the reasons just given, for a history of advantageousness to correlate with reliability of expression, and hence resistance to antiinnatia.

This quality-controlling effect implies that at different levels of intensity antiinnatia affects different characteristics, and consequently it enables not only the explanation of the characteristics of autism but also of general intelligence and its correlates.

Given the tendency of antiinnatia to suppress disadvantageous characteristics and leave advantageous ones, genes for antiinnatia would be highly and persistently advantageous. Furthermore, because of these advantageous effects, the more antiinnatia genes an individual has, the more healthy he will tend to be, and the more effective at getting on in life and in society (i.e., rising in social class, of which more further on).

But beyond a certain level of intensity antiinnatia would be disadvantageous, as considered in the next section.

\section{Excessive Antiinnatia}

Excessive antiinnatia would eliminate or suppress not only disadvantageous or neutral characteristics but also significantly advantageous, even vital ones. And some of 
those characteristics could be psychological ones.

Some readers may be sceptical of a notion that humans have innate tendencies or genetically 'hardwired' predispositions. However, such a view does not stand up well to examination. There is general agreement that animals, including primates, have innate predispositions. And it is not very controversial to suppose that heartbeats, breathing, and blushing inter alia are manifestations of central nervous system innate predispositions. Some persons nevertheless would appear to advocate that in respect of just one species, namely humans, certain aspects of the nervous system do not involve innate predispositions, namely those aspects that have to do with 'behaviour' as distinct from heartbeats, breathing, blushing, etc.. Arguments and evidence against this peculiar exclusion have been extensively presented elsewhere (e.g., Wilson, 1978).

Let us make this one very modest and reasonable assumption that humans do have innate behavioural tendencies. For convenience of exposition innate behavioural tendencies and the neural mechanisms producing them will be hereinafter referred to as innatons. Thus antiinnatia is here conceived of as producing loss/impairment/suppression of a diversity of innatons. Some suggestions of what particular innatons could be lost in autism will be presented later in the consideration of particular symptoms.

It will now be argued that the effects of antiinnatia would be particularly concentrated on psychological characteristics and appearance.

Most significant physiological characteristics are of necessity 'specified' within narrow margins; for example blood pressure and temperature. Reasons for this are (a) that the organism's physiology must work together as an integrated whole and this is only possible if the diverse elements are somewhat standardised; (b) fairly small variations, e.g., of blood pressure or temperature, can produce highly significant reductions of functioning with consequent elimination in natural selection.

By contrast, moderate idiosyncracies of innate behavioural tendencies would be advantageous rather than disadvantageous, because (a) uniformity of innate tendencies would tend to produce predictability, with consequent vulnerability to competitors and predators; (b) the diversity would tend to make individuals complement one another rather than compete to occupy the same narrow social roles or ecological niches.

Furthermore, moderate idiosyncracies of appearance, particularly of physiognomy, would likewise be advantageous because thereby biologically dominant individuals could mark their identity, and because families of indistinguishable individuals would be beset by problems.

It is well known that the conspicuous diversity (between and within species) of external appearance and behaviour conceals very great standardisation at the levels of physiology, cell types, and biochemistry (Futuyma, 1986). Thus characteristics other than morphology and behaviour tend to be highly longstanding.

It has already been argued that it is idiosyncracies that tend to be relatively affected by antiinnatia. Thus given these concentrations of idiosyncracies in behaviour and appearance we can expect to find excessive antiinnatia manifested as abnormality of behaviour combined with certain peculiarities of physical appearance. And given the highly conservative unidiosyncratic nature of the other aspects, excessive antiinnatia would not manifest as physical illness except perhaps in the severest cases.

\section{Causes and Correlates of Autism}

This section starts with a number of arguments leading to a particular conception of the relationship of autism to certain causes and correlates, then continues with consideration of empirical evidence relating to that conception.

It will not be proposed here that social class and IQ are causal factors in autism; but some explanation of their nature is necessary here for understanding of findings relating to them.

There is nothing that uniquely and invariably characterises human beings. They usually but not invariably have two eyes, ears, arms, etc., can use language, solve IQ tests, and so forth. But a fair proportion of humans' offspring are born without a brain, or like siamese twins do not have a whole body to themselves. And to define a human as one having human parents poses the equivalent question of what a 'human' parent is. Thus it is evident that humanness is a syndrome.

Just as there are variations between persons in the extent to which they have characteristics of schizophrenia or autism, so persons vary in the extent to which they have characteristics of 
humanness, in the extent to which random mutation and combination and chance events have made them atypical.

Some persons will be relatively distant from the core of the syndrome of humanness by reason of genetic abnormality of appearance or physical or behavioural functioning. They may be deficient in motivations, abilities, or physical capacities. It is obvious that such persons will generally tend to become relatively low in socioeconomic status (SES). This could well be the major reason why SES is correlated with good health and with IQ, even if not the only one.

It will be apparent from earlier pages that genes for antiinnatia will tend, by reducing idiosyncracies, to increase individuals' closeness to the core of the syndrome of humanness, and hence genes for antiinnatia will tend to be genes for high social class, in the sense described above. We would thus expect any cases of autism that are more hereditary than environmental to tend to come from higher social classes. (The co-involvement of heredity and environment will be considered more fully further on.)

There is much evidence that IQ (general intelligence, $g$ ) is a factor of individual differences that has major importance both personally and socially, and that in contemporary populations it is in substantial part non-cultural and inherited genetically (see e.g., Eysenck, 1979, 1982; Eysenck \& Kamin, 1981; Jensen, 1980). An indication of the great importance of IQ is the fact that a large number of persons differentiated solely by relatively low IQ are so unable to cope with ordinary life that they have to live in institutions for the mentally subnormal.

Given the existence of innatons and genetic diversity (from mutations and recombination), we would expect to find various odd innatons that interfere with effective mental functioning by producing idiosyncratic errors or slowings. For convenience of exposition these will be referred to as IQ impairers. Being disadvantageous, hence unreliable (as explained earlier), these IQ impairers would be highly sensitive to antiinnatia. Levels of antiinnatia too low to produce autism would affect the degree of expression of the IQ impairers and hence help to determine general intellectual efficiency, i.e., general IQ. Thus antiinnatia would be associated with high IQ. We would thus expect any cases of autism that are more hereditary than environmental to tend to have parents with above average IQ.

The disadvantageous IQ impairers would not be eliminated by natural selection because of the constraints on its perfecting power such as pleiotropy, recombination, and new mutations.

It has been remarked above that antiinnatia would be caused by both genetic and various environmental factors. Quite properly it is commonly thought that phenotypes are a product of interaction of genes and environment, and cannot be produced by one or other alone; but where a rare condition such as autism occurs it could be mainly due to one or other of two possibilities--a rare combination of genes or a rare environmental occurrence--and findings presented further on suggest that there is in fact something of a dichotomy within autism that corresponds to this.

The suggestion is that similar outcomes should result from the different causes, but this would not be exactly so, for the reason now illustrated with an analogy.

In this analogy machines correspond to people and corrosion corresponds to antiinnatia. If you store a number of machines in a damp room certain parts such as exposed iron and steel will rust, while other parts such as rubber and paintwork will not corrode. In other words there is a consistent syndrome of 'corrosion'. But supposing the machines are placed instead in a dry room, but there happen to be leakages of water through the roof, then while there will be something of the same pattern of corrosion as before, it will be less consistent and less complete, as some parts will be missed by the water while others will be particularly affected. Likewise the antiinnatia syndrome as produced mainly by environmental events could be less consistent than that produced mainly by genes for antiinnatia. Furthermore environmental factors would give a less 'pure' syndrome since they could produce collateral abnormalities peculiar to themselves (such as spots from an infection).

The conception that emerges from all this is of:

1. A relatively consistent syndrome that is mainly due to genes, and that is associated with high parental IQ and SES; and

2. Essentially the same syndrome but less consistently manifested and with collateral complications, mainly due to one of a diversity 
of environmental events, associated with average or below-average parental IQ and SES;

and we shall see that this is exactly what investigations of autism have found.

A diversity of environmental adversities have been associated with autism and appear to be causal (reviews include Prior, 1987, and Gillberg, 1988). Besides prenatal and perinatal conditions such as rubella and hypoxia, later developments can produce autism; for example Gillberg (1986) reports a case of 'typical autism' produced for 70 days in a 14 year old by herpes simplex encephalitis.

Folstein and Rutter (1988) and LeCouteur (1988) conclude that evidence suggests that genetics has an important role in causation of autism. The first three studies of table 1 add further support to this.

Smalley, Asarnov and Spence (1988) state that the data are not compatible with monogenic, autosomal recessive or $\mathrm{X}$-linked recessive inheritance for all cases; but that there could be multifactorial inheritance, as with IQ. This is further supported by the existence of a continuum ranging from severe autism through the much milder and more common Asperger's syndrome (Gillberg \& Gillberg, 1989; Frith, 1991) to normality.

Comparison of autistic persons having neurological signs--suggesting environmental causation--with those not having them finds that they have essentially the same syndrome of behaviours (Garreau, Barthelemy, Sauvage, Leddet, \& Lelord, 1984).

But the most noteworthy findings are those relating to social class and parental IQ.

Decades ago it was thought that findings indicated that parents of autistic persons tend to be of above-average social class (SES) and IQ. Subsequently Schopler, Andrews and Strupp (1979) proposed that these results had been entirely due to various factors biasing the sampling of the autistic population. Among other things it was suggested that lower-class parents would have lacked access to the information and expertise required for description and diagnosis of a then obscure condition; and they suggested that later studies avoiding these problems contradicted the earlier results. It will be argued here that sampling bias does not provide a credible explanation of the findings. And anyway, there need not be one absolute yes/no conclusion in respect of all times, places, and subtypes.
Schopler et al did not prove that sampling bias had occurred, but only showed that some conceivable biasing factors were indeed correlated with SES. And their hypothesis is challenged by a number of findings, including Lotter's particularly thorough survey, regarding which they could only suggest that Lotter's unspecified criterion of complex rituals may have been biased.

Sanua $(1986,1987)$ observed (a) that between earlier and later studies there was a broadening of the definition of autism to include individuals with evidence of organic causation or of brain damage; and (b) that all the studies that were claimed to show no upper-class bias in fact showed bimodal distributions of SES. He proposed that the bimodal distributions were due to combining of two separate phenomena, 'genuine' autism and similar conditions with organic (environmental) causes. The relationship of this distinction to the theory herewith will be readily apparent.

Three studies of parental SES identify (and compare) groups of organic vs non-organic or pure vs complicated. Their findings are shown in table 1 . The probability of all three being due to chance is substantially less than one in 5 million.

Cox, Rutter, Newman and Bartak (1975) did not use organicity as a criterion but did use a comparison group who were dysphasic, a condition they described as comparable in obscurity and severity to autism. Their results are also shown in table 1, and the probability of all four results being due to chance is substantially less than one in 100 million.

The sampling bias hypotheses were intended to account for the class distributions of autism in general; they were not intended to account for these differential findings. Quite what sampling biases would differentiate between organic/complicated and nonorganic/ /pure, or autistic and dysphasic? If these differentials really were due to some unknown sampling bias then it follows from the markedness of their results that there must have been a very great preponderance of autistic persons remaining undiscovered.

These results are in line with the general trend which is indicated in table 1 by the aggregated results of 15 studies (including some bimodal distributions); the preponderance of class I over class II has a high level of statistical significance $\left(p<10^{-20}\right)$. This suggests that sampling bias has not been a major influence in the generality of 
Table 1. Social class of parents of autistic persons as found in certain studies

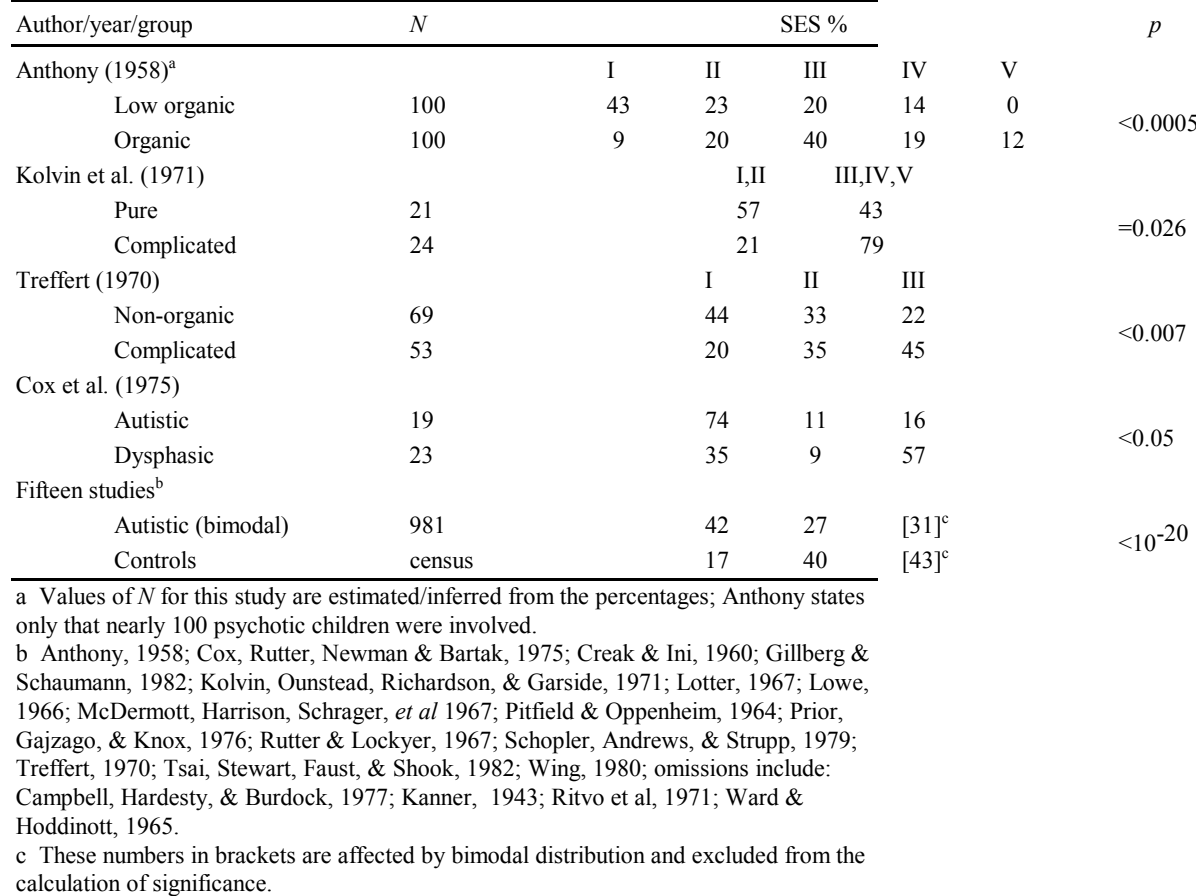

Anthony (1958)

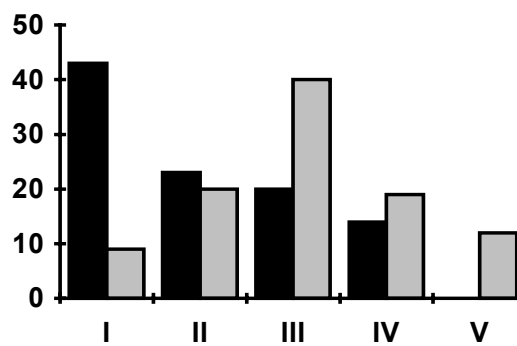

Low Organic 口Organic

Treffert (1970)

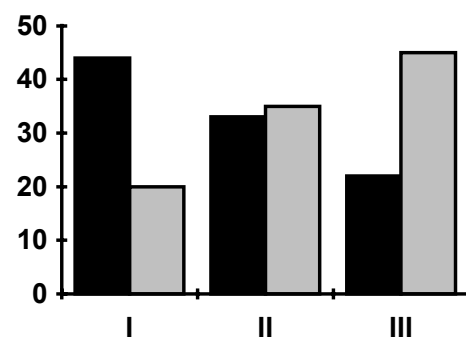

Non-organic

$\square$ Complicated

Kolvin et al (1971)

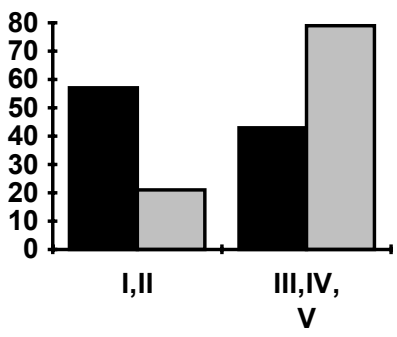

Pure

$\square$ Complicated 
studies.

In summary, these findings cannot seriously be squared with a hypothesis of sampling bias, whereas they concur excellently with the theory presented here. And they present the following challenge: what else could be the cause of these differential distributions? Could it be, perhaps, that something in caviar or champagne causes autism and that for some mysterious reason it produces the pure type rather than the complicated? And will this alternative explanation get to grips with many other facts about autism? The objective conclusion is surely that these differentials are powerful support for the theory.

The theory also provides explanation of another characteristic of the SES data, namely the discrepancies between studies at different times and places. Geographical differences may be partly accounted for by the differing distribution of differing persons; for example a rough, noisy area such as Camberwell, London (the location of Wing's study) would attract some sorts of persons and repel others, probably including those with characteristics of Asperger's syndrome.

But there is likely to be a more important process. During the last century there have been considerable unprecedented changes in the environment. These include changes in the chemicals in the air we breathe and in food and drink, and changes in medical technology, not least affecting the prenatal and perinatal environment. And not only is there the aforementioned evidence of involvement of perinatal conditions in autistic etiology, but also the finding of Wiedel and Coleman (1976) of a link with unspecified chemicals.

Now consider the effect of such environmental changes on the prevalence of the two categories of autistic persons, namely hereditary and environmental (note that because autistic persons rarely become parents the autism phenotype is subject to extreme natural deselection).

Suppose, firstly, a longstanding unchanging environment: there would then be a constant ratio of the two categories. Suppose that subsequently there is an increase in some ubiquitous environmental antiinnatia factors, perhaps air pollution. Thereupon certain genotypes that had previously been just below the threshold for autism would become autistic, and they would belong to the hereditary, SESlinked category (the environmental factor being ubiquitous). In due course, this new environment would reduce the frequency of high-antiinnatia genotypes in the population, and so the level of hereditary autism would fall again. Conversely, a reduction of the ubiquitous factors would result for a while in the virtual disappearance of hereditary autism, and so on. As regards nonubiquitous antiinnatia factors, such as obstetric adversities and infections, a different pattern would occur. If a rare perinatal adversity were to become somewhat more common, then obviously, autism of the environmental category would become more prevalent.

Methodologically impressive epidemiological studies are relatively easy to perform in certain countries, notably Japan and Sweden, because of systematic medical data collection covering the whole population. But that very fact attests to the atypicality of those nations in respect of technological sophistication; It follows that studies in contemporary Japan and Sweden could well show only a part of the dynamic pattern presented above.

The only epidemiological survey of the IQ of parents (Lotter, 1967) found substantially aboveaverage scores on the Mill Hill Vocabulary Scale $(p<0.005)$ and the Standard Progressive Matrices $\left(\chi^{2}(2, N=15)=98.7, p<10^{-20}\right)$. The other studies of parental IQ have given similar, though less marked results (Cantwell, Baker, \& Rutter, 1978). Members of Mensa (IQ > 148) have been found to have three to six times the normal frequency of autistic siblings and children (Sofaer \& Emery, 1981). though the significance of this is somewhat limited by the small number of cases. Because there is a substantial correlation between IQ and SES, and because this theory proposes similar bimodal distributions for both, these findings must be set in the context of the preceding discussion of evidence concerning SES.

\section{Sex Differences in Autism and in Intelligence Variance}

Well established findings are that about four times as many males as females are autistic, and that among the less disabled the ratio is even higher, about ten times (Wing, 1976; Lord, Schopler, \& Revicki, 1982).

These observations link up with the finding that most intelligence tests have greater variance for males than for females, and that an evoked potential correlate of IQ also has greater variance in males (standard deviation of 59 for males, 50 
for females) (Hendrickson, 1982). Hendrickson notes that such a difference corresponds to a male/female ratio of 5.5:1 above IQ 145 and of 47:1 above IQ 175.

There are straightforward evolutionary explanations for greater variance among males. An individual male can have many more offspring than an an individual female, and so exceptionality in a male can make more impact in natural selection. And in a social system where an 'alpha male' excludes all others from breeding, genes for reduced variance in males would be selected against.

The relative frequency of different phenotypes depends in substantial part on their probability of arising by random combination of genes and other factors. But the relative frequency of phenotypes also tends by definition to correlate with the relative biological advantageousness of those genotypes that tend to produce them. Hence arises the relative preponderance of exceptionality in males, as indicated by the IQ variances. But the translation from genotypes to phenotypes is, of course, not absolutely directly determinate, but rather involves a spread of probability, through the mediation of environment. Thus there will tend also to be a preponderance of closely related phenotypes (closely related in terms of cause rather than effect). And, it will be appreciated, according to the present theory the phenotype most closely related to the highly exceptional individual is the mildly autistic, and somewhat less closely related is the severely autistic. Thus there would be a marked preponderance of mildly autistic males, and a less marked preponderance of severely autistic males, as is found.

What other cause could there be for these observations?

\section{Emergent Characteristics}

When this theory was being developed it became clear that some features of the syndrome could not be credibly explained as simple impairments of innatons, most notably the distinctive rapid hand-flapping alternating with posturing. This led to the idea of "uncovering" (impairment of suppressors) of pre-human innatons, and thence to the following thoughts.

Some differences between a species and its immediate ancestor can be roughly categorised as gaining of a characteristic and losing of a characteristic. A characteristic that has had a long (multi-species) history of advantageousness is likely (as explained above) to be wellestablished in the sense of being very reliable, i.e., difficult to lose, and in that case losing of the characteristic may most readily result from evolution of a new characteristic that suppresses it. But this suppressing characteristic would tend to be less longstanding, less well-established and hence (as explained above) more vulnerable to antiinnatia. Hence the effect of antiinnatia would be to tend to suppress the suppressor and make the more-established older characteristic manifest again. Thus normal humans could feature suppressed genetic traces of innatons and physical characteristics common among humanity's antecedents, and the autistic syndrome could involve re-emergence of prehuman innatons and physical features.

Lest at this point some readers should be overcome with incredulity, the following should first be noted. Gould (1983) states that "the biological literature is studded with examples of these apparent reversions" (called atavisms) (p. 180). Indeed there is clear experimental demonstration of re-emergence of a characteristic not expressed for more than 80 million years (Kollar \& Fischer, 1980; Futuyma, 1986, p 4346). And a model of DNA organisation (Bodnar, 1988; Bodnar, Jones \& Ellis, 1989), with extensive empirical support, shows how information held in DNA "domains" may be suppressed or released by mutations or by environmental factors such as those causing cell differentiation; it also provides a mechanism for atavisms.

There is at least one example of an atavism being produced by both genetic and environmental factors independently, namely the tetraptera mutation in Drosophila. This mutation produces reversion to the four-winged condition that is the norm in higher insects. An identical effect--a phenocopy--can be produced by subjecting normal Drosophila (which have the gene to suppress the extra wings) to either heat shock or ether at a critical stage of development.

However, these reminiscences from evolutionary history could be far from perfect or comprehensive, because of the distortions produced by more recent selection pressures. 


\section{Physical Appearance in Autism}

It was argued above that excessive antiinnatia would affect physical appearance, and particularly would reduce idiosyncracies and perhaps also produce emergence of some prehuman physical features. In addition, or alternatively there could be loss of humanspecific features (idiosyncracies common to the species), giving tendency towards the average mammalian form.

It was demonstrated by Francis Galton that attractiveness of appearance is largely a matter of averageness, of absence of idiosyncracies. Such results have recently been found to be independent of race and culture (Langlois \& Roggman, 1990). Thus because antiinnatia tends to suppress idiosyncracies it should be expected to increase attractiveness of appearance. And in fact, there have been recurrent observations to the effect of autistic persons being of 'intelligentlooking', 'attractive' appearance. And Walker (1976) found significant occurrences of stigmata as follows: low seating of ears: $P<0.001$; wide spacing of eyes: $P<.01$; webbing of toes: $P<$ 0.01 . These stigmata do seem to have a prehuman character but we do not see what might seem more obviously expected, for example fur and a tail. But surely there are other relevant factors involved which account for this discrepancy, namely the complexity and improbability of the genetic coding required for a characteristic, the force of recent selection of the suppression, and the greater importance (in natural selection) and hence reliability of such things as lacks of tails and fur as opposed to slight deviations of form.

\section{Abnormalities of the Brain in Autism}

It was argued earlier that excessive antiinnatia would produce behavioural abnormalities by preventing or impairing the expression of a diversity of innatons. This could involve primary abnormalities in numerous parts of the brain.

Investigations of brain pathology in autism have found a diversity of abnormalities but none of them have been found to be consistently present (reviewed by Prior, 1987, and Gillberg, 1988).

It is not at present possible to discern whether these observed abnormalities are causal of autistic symptoms or are merely collateral occurrences. And it has been argued by
Ciaranello, Vandenberg, \& Anders (1982) that the causal abnormalities would be in fine details such as elongation of dendrites and axons, synapse formation or establishment of connections with surrounding neural elements. They suggest that "lesions at this stage might be so morphologically subtle as to escape detection with conventional techniques yet have profound clinical consequences".

Goodman (1989) noted that there is a conspicuous lack of agreement about what is the primary neurological abnormality (brainstem and reticular formation (Hutt, Hutt, Lee \& Ounsted, 1965; Ornitz, 1985; Rimland, 1964), left hemisphere (McCann, 1981; Prior, 1979), mesolimbic system (Damasio \& Maurer, 1978; Peters, 1986), cerebellum (Courchesne et al, 1988)), and of what is the primary psychological abnormality (social/affective (Fein, Pennington, Markowitz, Braverman \& Waterhouse, 1986; Hobson, 1989), recognition/memory (Boucher \& Warrington, 1976; Rimland, 1964), handling of complex symbols (Ricks \& Wing, 1975), theory of mind (Leslie, 1987), lack of motivation to understand (Frith, 1989)). This led Goodman to favour the idea of a shared vulnerability of several neural systems, involving genetic and environmental factors. Such multiple primary abnormalities had already been proposed by Wing and Wing (1971). These proposals are obviously in agreement with the present theory.

\section{Abnormalities of Behaviour in Autism}

All that remains to be accounted for by the theory is the most significant set of facts about autism: the syndrome of behavioural abnormalities.

Table 2 gives a list of characteristics of autistic persons; there are additions to Wing's (1976) table because it was concerned only with clinical features, and because there have been subsequent developments.

It will be appreciated that with the current limited state of understanding of the mechanisms by which neurons produce behaviour it is not possible to specify the physical form of any of the innaton mechanisms, nor of how they produce their presumed effects. Nor is it practicable to provide conclusive arguments of involvement of innatons in respect of all of the items. But it should be possible to show that there are here a substantial number of abnormalities that can all be plausibly supposed 
to be caused by loss of innatons, and in many cases strong grounds for hypothesising innate involvement.

Turning to table 2, we come first to disorders of communication. A theory of innate predispositions in language has already been proposed by Chomsky (1957) but it is difficult to see any relationship of that theory to these symptoms; hence the present theory and Chomsky's do not seem to offer one another much support at this point. But it seems quite conceivable that Chomsky's universal grammar would not be notably vulnerable to antiinnatia because its mechanism would be relatively simple and hence reliable.

And yet there are a number of facts that strongly point to the conclusion that there is some innate predisposition in language development: (a) language learning is easier for young children than for adults, in striking contrast to the general trend of increase in ability and skills throughout childhood and adolescence--it is surely remarkable that the stupendous task of learning the meanings of words and grammar without the aid of any dictionary or translation can be achieved by children who are in other respects very simple-minded, while intelligent adults take degree courses to achieve a lesser task in nonnative languages; (b) humans very consistently develop language competence regardless of environmental impediments and intellectual deficiencies, yet efforts to teach nonhumans have consistently failed to reach beyond a very basic level; (c) damage to certain parts of the brain produces impairments highly specific to language; (d) there is a great difference between pidgins and creoles (Bickerton, 1984).

If a person hears utterances in a language unrelated to any he already knows he will not be able to distinguish in what way the various phonemes are grouped into words, since generally speaking words flow into one another without a break, i.e., those spaces between words as on this page do not have a counterpart in the sounds of the language. Would you guess, for example, how to divide up the following utterances in Cornish and Japanese respectively?: "Unscuberchymblssquythawrukentradhejapelhac usaynuogell."

"Watasiwasukosimoikitakunakattanodesugatooto oikaseraretesimaimasita."

Even when forewarned that utterances contain separately meaningful words it must be difficult to discover them, but in the absence of an innate predisposition to search for such words certain characteristics of autistic persons seem inevitable: complete failure of comprehension, and the perfect reproduction of utterances in their entirety as semantic units. And it is remarkable that some autistic persons can read in the sense of translating from printed letters to speech (which 14\% of the population of the USA cannot currently do), yet completely lack comprehension (Silberberg \& Silberberg, 1967; Snowling \& Frith, 1986).

Probably there is also a predisposition towards forming of a conception of and monitoring of the mental state of others, of their intentions, information, assumptions and points of view (this has been conveniently labelled a "theory of mind"). Its absence could manifest not only in the mixing up of 'you' and 'I', but also in certain 'pragmatic' failures of communication (pragmatics is defined by Bates (1976) as use of speech and gesture in a communicative way, appropriate to the social context).

Pragmatic deficiencies identified by Paul (1987) and Volkmar (1987) are:

1. Lack of use of non-linguistic knowledge in interpreting sentences (e.g., "Colour this circle blue" is only understood if preceded by "I'm going to tell you to do some things").

2. Difficulty in judging how much and what pieces of information are relevant in response to enquiries. (e.g., "Did you do anything at the weekend besides raking leaves?" "No".)

3.Difficulty in identifying the topic initiated by the other.

4. Failure to establish joint frame of reference, e.g., beginning discussion without providing adequate background information.

5. Failure to take social norms or listeners' feelings into account (e,g., "You're very fat").

6. Reliance on limited conventional stratagems of conversation or stereotyped expressions (e.g., "Do you know about Cambodia").

The notion of "theory of mind" is also supported by experimental evidence of inability to attribute false beliefs to others (Baron-Cohen, Leslie, \& Frith, 1985; deGelder, 1987; Leslie \& Frith, 1987); and quite how does the hypothesised 'theory of mind' come about except innately?

Leslie (1987) has proposed innate mechanisms (an expression raiser, a manipulator, and an interpreter) to account for pretend play and the 
manifestations of 'theory of mind'. This scheme seems unnecessarily complex--all that is required is innate concepts (or preparedness for concepts) of others having beliefs and attitudes, coupled with the awareness, possibly innate, that such beliefs do not have to be true or logical.

Baron-Cohen (1988) observes that Leslie's innateness theory accounts well for some findings about autism, while others are better explained by Hobson's (1989) theory of innate mechanisms for expression of emotions and their recognition in others. But the theory presented here accounts not only for all these findings but also for the many others indicated in this paper.

It seems likely that the development of language and non-verbal communication depends on not only the abilities of comprehension and expression but also on motivation. Probably a motivation to influence others (to get them to help, etc.) would be an inadequate basis for the learning of communication skills if not accompanied by a motivation towards informing and expressing for its own sake. Only a small proportion of human communication consists of appeals, requests, or inducements to perform desired actions; informing and expressing predominate. Deficiency of such a motivation is suggested by the lack of joint attention behaviours (item 18), the tendency to communicate only to request some favour, and the complete absence of expressive gestures even though instrumental gestures are used (Attwood, Frith, \& Hermelin, 1988). Deficits of joint attention gestural behaviours (pointing, showing) are found to predict subsequent language development in autism (Mundy, Sigman \& Kasari, 1990). Such motivation and behaviour would presumably either be innate or a consequence of innate reward contingencies.

It also seems parsimonious to assume that nonverbal communication involves in humans as in animals, innatons for its generation and reception.

Certain other characteristics of autism appear to relate to processes that must have an innate element, as will now be considered.

As with the other sensory organs, there must be some innate neural mechanism for detecting and interpreting movement of the fluid in the balance-sensing labyrinths of the inner ear, and deficiency of that mechanism would prevent dizziness caused by the inertial flow of the fluid after spinning (item 4).

A number of the features listed in table 2 could be explained in terms of deficiency of imitating, namely poor control of pitch, volume, intonation and pronunciation, deficiency of non-verbal communication, problems of motor imitation, erratic eating and drinking, lack of pretend play, and the various abnormalities of social functioning (items 2, 3, 6, 8-16, 18, and parts of 1 ), though it seems more likely that most of these involve loss of specific innatons. But surely, the normal tendency to imitate must itself be innate, and hence all the abovementioned must be dependent one way or another on innatons. It might be objected that imitation could be learned by operant conditioning, but this would still depend on something (namely innatons) providing specifications of what constitutes 'reward', 'punishment', and 'imitation'.

Indifference to some sensory experiences could occur if innatons for interpreting or reacting were impaired. How else could the orienting response arise other than innately?

The clumsiness of some autistic persons could be due to dysfunction of innatons either directly involved in controlling or coordinating movements, or involved in providing the feedback required for appropriateness of the movements. The alternative gracefulness and nimbleness will be considered further on.

The unusually accurate memory (item 24) can be understood in terms of a lack of innatons that normally produce categorisation, coding, grouping, compartmentalising, or other processing of data. For example, normals remember sentences not as strings of letters or sounds but as strings of words. Hermelin and O'Connor (1970) found that unlike normals, autistic persons do not find meaningful sentences easier to remember than meaningless ones. The intense resistance to small changes in the environment (as opposed to a complete change of environment) could well be a result of the difficulty the unprocessed memory has in adapting to such partial change--the need 
Table 2. Characteristics of autistic persons (a rearrangement of the table of Wing, 1976, with additions)

\section{A. Effects of nonfunctioning of innatons}

1. Disorders of communication:

*Problems in comprehension of speech.

*Complete absence of speech (mutism) or, in those children who do speak:

* -Immediate echolalia (parrot-like copying).

* -Delayed echolalia.

* -Repetitive, stereotyped, inflexible use of words and phrases.

* -Confusion over the use of pronouns.

* -Immaturity of grammatical structures in spontaneous (not echoed) speech.

*Poor control of pitch, volume and intonation of the voice. Problems of pronunciation.

*Poor comprehension of the information conveyed by gestures, miming, facial expression, bodily posture, vocal intonation, etc.

*Lack of use of gesture, miming, facial expression, bodily posture and vocal intonation to convey information. 'Pragmatic' deficiencies of verbal communication (see text).

2. Problems of motor imitation: difficulty in copying movements; muddling right-left, up-down, and back-front.

3. Erratic patterns of eating and drinking, including consumption of large quantities of fluid [also category C].

4. Lack of dizziness after spinning round.

5. *Apparent aloofness and indifference to other people, especially other children.

6. $\quad *$ Lack of imaginative play or creative activities.

7. *Attending to minor or trivial aspects of people or objects instead of attending to the whole.

8. Socially immature and difficult behaviour.

9. Failure to use gaze, facial expression, posture and gesture to regulate social interaction. ${ }^{\text {a }}$

10. Rarely seeking others for comfort or affection. ${ }^{\text {a }}$

11. Rarely offering comfort or responding to others' distress or happiness. ${ }^{\text {a }}$

12. Rarely initiating interactive play with others. ${ }^{\mathrm{a}}$

13. Rarely greeting others. ${ }^{\mathrm{a}}$

14. No peer friendships in terms of mutual sharing of interests, activities and emotions--despite ample opportunities. ${ }^{\text {a }}$

15. Lack of reciprocal eye-contact and social smile in first months. ${ }^{\text {a }}$

16. Normal attachments not present when expected. ${ }^{\mathrm{b}}$

17. Rarely imitating, even when motivated. ${ }^{\mathrm{c}}$

18. Deficit of joint attention behaviours (i.e., showing an object or pointing). ${ }^{\mathrm{c}}$

\section{B. Less direct effects of nonfunctioning of innatons}

19. Abnormal responses to sensory experiences (indifference, fascination).

20. Spontaneous large movements, or fine skilled movements, or both may be clumsy in some children though others appear to be graceful and nimble.

21. *An unusual form of memory: the ability to store items for prolonged periods in the exact form they were first experienced.

22. *Intense resistance to change, attachment to objects and routines or a repetitive, uncreative interest in certain subjects.

23. *Absorption in repetitive activities, stereotyped movements, self-injury, etc.

\section{Emergences of long-established innatons}

24. Abnormal responses to sensory experiences (distress).

25. Abnormal responses to pain and cold.

26. The use of peripheral rather than central visual fields [and or category A].

27. Looking at people and things with brief flashing glances rather than a steady gaze [and or category A].

28. Jumping, flapping limbs (i.e. alternate handflapping and posturing, ${ }^{\mathrm{d}}$ rocking, and grimacing).

29. A springy tip-toe walk without appropriate swinging of the arms.

30. An odd posture when standing, with head bowed, arms flexed at the elbow and hands drooping at the wrist.

31. Erratic patterns of sleeping and resistance to the effects of sedatives and hypnotics [and or category A].

32. *Inappropriate emotional reactions [and or category A].

\section{Other suppressions of relatively idiosyncratic characteristics}

33. Immaturity of general appearance and unusual symmetry of face. (Attractive appearance, and intelligent appearance, and or stigmata such as low seating of ears, wide spacing of eyes, and partial webbing of toes. ${ }^{\mathrm{e}}$ )

34. *Skills that do not involve language, including music, arithmetic, dismantling and assembling mechanical or electrical objects, fitting together jigsaw or constructional toys. (Some very retarded can read words out loud. ${ }^{f}$ )

\footnotetext{
* items essential for diagnosis of autism as described by Kanner (1943).

a Rutter \& Schopler (1987). b Volkmar (1987). c Sigman, Ungerer, Mundy \& Sherman (1987).

d Walker \& Coleman (1976). e Walker (1976).

f Silberberg \& Silberberg, 1967; Snowling \& Frith, 1986; Welsh, Pennington, \& Rogers, 1987)
} 
to start the memorising all over again. Perhaps there are innatons in normal memory processes for the avoidance of such problems.

It seems reasonable to suppose that a person having many or all of the characteristics of items 1 to 18 and 24 to 32 would find life confusing and unpredictable in many ways. This would result in stress and distress that could be alleviated by reassuring, predictable data, and items 19,22 , and 23 are probably in part a manifestation of this seeking of predictable, reassuring data (perhaps in item 19 'fascination' may be a slight misinterpretation). This accords with the finding that these behaviours are more frequent in unfamiliar circumstances (Runco, Charlop, \& Schreibman, 1986).

It has been proposed (Lovaas, Newsom, \& Hickman, 1987) that a number of autistic behaviours including these latter involve selfstimulation, and result from the resulting 'perceptual reinforcement'. This is consonant with the above but fails to explain why certain peculiar behaviours have this self-reinforcing quality exclusively in autism (e.g., the distinctive handflapping, of which more below), nor why the behaviours are characteristically repetitive and predictable. Surely, the repetitiveness/predictability is because the reassurance is rewarding hence reinforcing; and surely the particular repertoire of behaviours available for reinforcement depends on what innatons the individual has--which ties in with the idea that autistic persons have emergences of pre-human innatons.

A number of autistic characteristics seem strongly suggestive of emergences of pre-human innatons; indeed that is how the idea originated. There now follows a presentation of specific instances, then a consideration of the general merits of these explanations.

Autistic persons' short periods of rapid handflapping and posturing are suggestive of the bursts of running alternating with rigidity that are seen in birds, squirrels and rats in certain wild contexts. We do not see foot-flapping such as would produce running, presumably because it has been substantially suppressed by natural selection. However, the mean periodicity of the hand-flapping rate ( 0.26 seconds) and its mean duration (1.76 seconds) and the mean duration of posturing (1.85 seconds) (Walker \& Coleman, 1976) all correspond well to the characteristics of the squirrel and rat behaviours (though these same measurements are re-reported as $0.25,3.51$, and 3.67 seconds by Coleman, 1978).

Item 29 suggests the walking manner of a nonhuman primate, in addition to which walking on toes rather than heels is the norm in mammals.

A species idiosyncracy of humans is their upright posture. Most animals stand on four legs, and when such animals stand on rear legs alone they characteristically position their front legs ready to meet the ground when they fall down to it, and they position their heads drooping downwards since otherwise their eyes, ears, mouth, and nose would be pointing upwards. It seems that these same predispositions can be seen in autistic persons (item 30).

Innatons are probably also involved in ensuring that eating and drinking are regulated to the requirements of the digestive system. Innatons more appropriate to animals of different size and with different digestive systems could cause the abnormalities of eating and drinking.

Regarding item 24, a case has been reported of extreme distress induced by the presence of a silver teapot (Wing, 1976), and a similar case involved a silvery spoon with an ornate end. It is well-known that phobias are usually evoked by evolutionarily long-standing stimuli (rather than by guns, electric wires, etc.). It is notable that in both the present cases a silvery object with one plane of symmetry and of complicated shape was involved. In the pre-human world there would have been no teapots or spoons, and such a shape would usually be indicative of an animal, and if a silvery one, perhaps a reptilian predator just emerged from water.

The jumping, rocking and grimacing of some autistic persons may be a reappearance of nonverbal communications/expressions of prehuman primates.

These hypotheses of emergent innatons are not very testable at present but at least they provide explanation of a number of very peculiar phenomena in terms of a few well-established biological principles, as indicated earlier. The alternative to these explanations is to suppose that by some freak of improbability "it just so happens" that abnormal brain functioning produces this particular pattern of hand-flapping and posturing resembling a common animal behaviour, and "it just so happens" that it also produces this particular standing posture resembling that of four-legged animals, and "it just so happens" that it also produces the manner of walking of most mammals, and "it just so 
happens" that it also makes infants scared of teapots and spoons that resemble animals in their plane of symmetry, ...(not to mention all the other facts about autism here integrated together by antiinnatia). In the past fifty years no other alternatives to these "just so" non-explanations have emerged.

It might be casually supposed that emergence of innatons could just as credibly account for any conceivable abnormality; but, then, supposing that autistic persons walk on their heels, adopt the postures of ballet dancers, and flap their tongues rather than their hands, what are the equally credible explanations?

It is not necessary to suppose that all the behavioural abnormalities are primary manifestations of lacks of innatons or emergences of pre-human ones. The suggestion of Carr and Durand (1987) that autistic persons' aggression and tantrums occur because of lack of any more appropriate means of expression is fully compatible with this theory.

Two remaining characteristics in table 1, namely gracefulness and nimbleness, and special skills, seem rather unlikely concomitants of a severe pervasive disabling disorder, but they are quite in harmony with the theory presented above. They may be simply accounted for as further manifestations of the 'quality-controlling' effect of antiinnatia, as already exemplified by the attractive appearance of autistic persons and the link with high parental IQ and SES. This may also be the cause of the finding that many (though not all) autistic children show relatively great imagination and productivity in drawing (Boldyreva, 1974).

An important fact about autism is that while a significant minority of autistic persons are of average to high IQ, the majority are markedly subnormal with IQ below 70. According to the theory all these autistic persons have the characteristic that normally produces high IQ, namely high suppression of IQ impairers, as explained earlier. But if the excessive antiinnatia also suppresses certain other innatons necessary for effective mental functioning, such as innatons for language skill, then low IQ will nevertheless result. Unequal impairment of different IQaiding innatons would account for the notoriously uneven scores on intelligence subtests (Lockyer \& Rutter, 1970), which is exaggerated in some individuals (idiots savants), probably by constant selective practice and social reinforcement of their single competence.

Certain EEG waveforms have been found to show marked correlations with IQ (e.g., Ertl, 1968; Ertl \& Schafer, 1969; Shucard \& Horn, 1972; Hendrickson, 1982). The theory of IQ associated with this theory of autism includes a mechanism which in computer simulation reproduces the shape of these waveforms; in this mechanism interindividual differences in the waveforms are determined by the degree of suppression of the IQ impairers. Thus it is to be expected that idiots savants and autistics would have waveforms such as are usually associated with high IQ despite being of low or unmeasureable test-measured IQ. This could be a useful aid to diagnosis.

\section{Concluding Discussion}

Numerous other theories of autism have been proposed, but none of them address more than a fraction of the findings presented here, and few attempt any explanation of why such a severe disorder exists and is not extremely rare. So with good reason there has continued to be a widespread view that the syndrome constitutes an unresolved mystery. The present paper has argued that excessive general impairment of gene expression can be expected to manifest as abnormality of behaviour and appearance, with certain relationships to high parental SES and IQ and environmental factors, and a peculiar sex distribution. The autistic syndrome is shown to accord fully with the requirements, whereas other psychiatric syndromes cannot be credibly conceived as doing so. A remarkable diversity of facts about autism challenge the theory, but they all prove consonant with it. Thus, though no scientific theory can be absolutely proved correct, the reasonable conclusion is surely that the autistic syndrome no longer presents a mystery, except in respect of many important details yet to be fully elucidated.

An obvious shortcoming of the theory as presented here is that it provides little or no description, physical or chemical, of the mechanisms of the innatons and antiinnatia. This is unavoidable at present because so much remains unknown about, on the one hand, the precise brain mechanisms that produce behaviour, and on the other hand, the processes controlling gene-expression. if such detailed 
information becomes available then according to this theory it may be possible to develop drugs to adjust gene-expression such as to prevent or cure autism. Research to date in neuroscience and gene-expression does not seem to indicate any obvious starting points for investigation, other than the possibility of drugs to reduce the prevalence of proteins that tend to bind randomly to DNA. Perhaps other fruitful starting points could be provided by the etiological factors associated with autism. For example, information emerging about the molecularbiological effects of rubella and herpes virus, or of abnormality of the genome associated with autism, could be interpreted in the light of the theory.

The theory does not imply that there is no value in psychological forms of therapy, such as holding therapy, special learning programs, or specially modified environments or routines.

It has been suggested by some readers that the present paper has to a substantial extent unwittingly retrodden the same ground as Rimland's 1964 book, and arrived at mostly the same conclusions.

At a time when autism was widely thought to be caused by inappropriate behaviour of parents, Rimland argued against that hypothesis in favour of the conception, that accords with the present theory, of autism resulting from genetic and nonpsychological environmental factors.

He also argued that the findings of aboveaverage parental IQ and SES were not attributable to sampling bias. However, his conclusion was subsequently discredited (so it seemed) by the accumulation of subsequent studies that showed no relationship anyway (Schopler et al, 1979, and subsequent). Rimland further proposed that an excess of genes for high IQ tended to produce a vulnerability to autism. The theory presented here concurs with this, but goes further by presenting an explanation of why this would be so, in terms of antiinnatia and IQimpairing innatons.

The present theory also differs from Rimland (1964) in his positing a single primary disability (inability to relate new stimuli to remembered experience). The fable of the blind men and the elephant comes to mind (they described it in turn as like a tree trunk, a snake, a leaf). Over the years a number of suggestions have been made of what might be a primary psychological or neurological abnormality in autism (listed earlier). Quite possibly most of these are correct as partial accounts of aspects of autism. And their authors were not unreasonable in doubting the validity of other aspects of the then uncertain syndrome. But the suggestion of the present paper is that more or less the whole of the "elephant" has been genuine all along.

Finally, a few words about criteria for evaluation of theories.

There has recently become widespread a view that to be worthy of publication a theory must present precise and readily testable hypotheses and predictions. I agree that these are worthy qualities in a theory, and regret that that presented here is still at some points deficient in this respect. But it seems to me that there is a more important quality that a theory can have, against which precision and ease of refutation are only secondary. This is what we might call its degree of harmony with the totality of facts, its explaining power, the degree to which it encompasses a whole spread of observations within a scheme of a few basic hypotheses, and integrates them with the canon of existing understanding. Should any reader think this to be an easy quality to obtain, I commend to their consideration the numerous previous theories of autism, of which only a few have been cited here.

There is no reason to presume that reality has been specially designed for the convenience of investigators conducting empirical tests, and those who effectively make that presumption censor themselves from any understanding that does not conform to their preconception. 


\section{References}

Anthony J. (1958) An experimental approach to the psychotherapy of childhood autism. $B r . J$. med. Psychol. 31, 211-225.

Asperger H. (1944) Die "Autistichen Psychopathen" im Kindersalter. Arch. Psychiat. NervKrankh. 117, 76-136.(English translation in Frith, 1991)

Attwood A., Frith U. and Hermelin B. (1988) The understanding and use of interpersonal gestures by autistic and Down's syndrome children. J. Autism dev. Disorders 18, 241257.

Baron-Cohen S. (1988) Social and pragmatic deficits in autism: cognitive or affective? $J$. Autism dev. Disorders 18, 379-402.

Baron-Cohen S., Leslie A. M. and Frith U. (1985) Does the autistic child have a 'theory of mind'? Cognition 21, 37-46.

Bates E. (1976) Language in Context. Academic Press, New York.

Bickerton D. (1984) The language bioprogram hypothesis. Behavioral brain Sciences 7, 173221.

Bodnar J. W. (1988) A domain model for eukaryotic DNA organisation: A molecular basis for cell differentiation and chromosome evolution. J. theor. Biol. 132, 479-507.

Bodnar J. W., Jones G. S. and Ellis C. H. (1989) The domain model for eukaryotic DNA organisation 2: A molecular basis for constraints on development and evolution. $J$. theor. Biol. 137, 281-320.

Boldyreva S. A. (1974) Risunki Detei Doshkolnogo Vostrasta Bol'nykh Shizofreniei. Meditsina, Moscow.

Boucher J. and Warrington E. K. (1976) Memory deficits in early infantile autism. $B r . J$. Psychol. 67, 73-87.

Campbell M., Hardesty A. and Burdock E. (1977, October) Selected peri- and postnatal and demographic characteristics of autistic children. Paper presented at the annual meeting of the American Academy of Child Psychiatry, Dallas, Texas.

Cantwell D. P., Baker L. and Rutter M. (1978) Family factors. In Autism (Edited by Rutter M. and Schopler, E.). Plenum, New York.

Carr E. G. and Durand V. M. (1987) See me, help me. Psychol. Today 21 (11), 62-64.

Chomsky N. (1957) Syntactic Structures. Mouton, The Hague.
Ciaranello R. D., VandenBerg S. R. and Anders T. F. (1982) Intrinsic and extrinsic determinants of neuronal development. $J$. Autism dev. Disorders 12, 115-145.

Coleman M. (1978) A report on the autistic syndromes. In Autism (Edited by Rutter, M. and Schopler, E.). Plenum, New York.

Courchesne E., Yeung-Courchesne R., Press G. A., Hesselink J. and Jernigan T. (1988) Hypoplasia of cerebellar vermal lobules VI and VII in autism. New Engl. J. med. 318, 1349-1354.

Cox A., Rutter M., Newman S. and Bartak L. (1975) A comparative study of infantile autism and specific developmental receptive language disorder. Br. J. Psychiat. 126, 146-159.

Creak M. and Ini S. (1960) Families of psychotic children. J.child Psychol. Psychiat. 1, 156175.

Damasio A. R. and Maurer R. G. (1978) A neurological model for childhood autism. Archs Neurol. 35, 777-786.

de Gelder B. (1987) On not having a theory of mind. Cognition 27, 285-290.

Ertl J. P. (1968) Evoked potentials, neural efficiency and IQ. In International Symposium on Biocybernetics, Washington, D.C., 1968. Churchill, Edinburgh.

Ertl J. P. and Schafer D. W. (1969) Brain response correlates of psychometric intelligence. Nature 223, 421-422.

Eysenck H. J. (1979) The Structure and Measurement of Intelligence.Springer, New York.

Eysenck H. J. (Ed.) (1982) A Model for Intelligence. Springer, New York.

Eysenck H. J. and Kamin L. (1981) Intelligence, the Battle for the Mind. Pan, London.

Fein D., Pennington B., Markowitz P., Braverman M. and Waterhouse L. (1986) Towards a neuropsychological model of infantile autism: are the social deficits primary? J. Am. Acad. child Psychiat. 25, 198212.

Folstein S. and Rutter M. (1988) Autism: Familial aggregation and genetic implications. J. Autism dev. Disorders 18, 3-30.

Frith U. (1989) Autism: Explaining the Enigma. Blackwell, Oxford.

Frith U. (Ed.) (1991) Autism and Asperger Syndrome. Cambridge University Press.

Futuyma D. J. (1986) Evolutionary Biology. Sinauer, Sunderland, Mass. 
Garreau B., Barthelemy C., Sauvage D., Leddet I. and Lelord G. (1984) A comparison of autistic syndromes with and without associated neurological problems. J. Autism dev.

Disorders 14, 105-111.

Gillberg C. (1986) Brief report: Onset at age 14 of a typical autistic syndrome: A case report of a girl with herpes simplex encephalitis. $J$. Autism dev. Disorders 16, 369-375.

Gillberg C. (1988). The neurobiology of infantile autism. J. child Psychol. Psychiat. 29, 257266.

Gillberg I. C. and Gillberg C. (1989) Asperger syndrome: Some epidemiological considerations: A research note. J. child Psychol. Psychiat. 30, 631-638.

Gillberg C. and Schaumann H. (1982) Social class and infantile autism. J. Autism dev. Disorders 12, 223-228.

Goodman R. (1989) Infantile autism: a syndrome of multiple primary deficits? J. Autism dev. Disorders 19, 409-424.

Gould S. J. (1983) Hens' Teeth and Horses' Toes. Norton, New York.

He X., Ingraham H. A., Simmons D. M., Treacy M. N., Rosenfeld M. G. and Swanson L. W. (1989) Expression of a large family of poudomain regulatory genes in mammalian brain development. Nature 340, 35-42.

Hendrickson D. E. (1982) The biological basis of intelligence. Part 2: Measurement. In A Model for Intelligence (Edited by Eysenck H. J.). Springer, New York.

Hermelin B. and O'Connor N. (1970) Psychological Experiments with Autistic Children. Pergamon, Oxford.

Hobson R. P. (1989) Beyond cognition: A theory of autism. In Autism: nature, diagnosis and treatment (Edited by Dawson G.). Guildford, New York.

Hutt S. J., Hutt C., Lee D. and Ounsted C. (1965) A behavioural and electroencephalographic study of autistic children. J. psychiat. Res. $\mathbf{3}$, 181-197.

Jensen A. R. (1980) Bias in Mental Testing. Methuen, London.

Kanner L. (1943) Autistic disturbances of affective contact. Nerv. Child 2, 217-250.

Kanner L. (1973) Childhood psychosis: Initial studies and new insights. Winston, Washington D.C.

Kollar E. J. and Fischer C. (1980) Tooth induction in chick epithelium: expression of quiescent genes for enamel synthesis. Science 207, 993-995.

Kolvin I., Ounstead C., Richardson L. M. and Garside R. F. (1971) Studies in childhood psychoses: III. The family and social background in childhood psychoses. $\mathrm{Br}$. $J$. Psychiat. 118, 396-402.

Langlois J. H. and Roggman L. A. (1990) Attractive faces are only averages. Psychol. Science 1, 115-121.

LeCouteur A. (1988) The role of genetics in the aetiology of autism. In Aspects of Autism (Edited by Wing L.). Gaskell, London.

Leslie A. (1987) Pretense and representation: The origins of a theory of mind. Psychol. Rev. 94, 412-426.

Leslie A. M. and Frith U. (1987) Metarepresentation and autism: How not to lose one's marbles. Cognition 27, 291-294.

Lockyer L. and Rutter M. (1970) A five to fifteen year follow-up study of infantile psychosis. IV. Patterns of cognitive ability. Br. J. soc. clin. Psychol. 31, 152-163.

Lord C., Schopler E. and Revicki D. (1982) Sex Differences in autism.J. Autism dev. Disorders 12, 317.

Lotter V. (1967) Epidemiology of autistic conditions in young children: some characteristics of the parents and children.Soc. Psychiat. 1, 163-173.

Lovaas I., Newsom C. and Hickman C. (1987) Self-stimulatory behaviour and perceptual reinforcement. J. appl. Behavior Analysis 20, 45-68.

Lowe L. H. (1966) Families of children with early childhood schizophrenia: selected demographic information. Archs gen. Psychiat. 14, 26-30.

McCann R. S. (1981) Hemispheric assymmetries and infantile autism. J. Autism dev. Disorders 11, 401-411.

McDermott J. F., Harrison S. I., Schrager J., Lindy J. and Killins E. (1967) Social class and mental illness in children: The question of childhood psychosis. Am. J. Orthopsychiat. 37, 548-557.

Mundy P., Sigman M. and Kasari C. (1990) A longitudinal study of joint attention and language development in autistic children. $J$. Autism dev. Disorders 20, 115-128.

Ornitz E. M. (1985) Neuropsychology of infantile autism. J. Am. Acad. child Psychiat. 24, 85-124. 
Paul R. (1987) Communication. In Handbook of Autism (Edited by Cohen D. J. and Donellan A. M.). Wiley, New York.

Pitfield M. and Oppenheim A. N. (1964) Child rearing attitudes of mothers of psychotic children. J. child Psychol. Psychiat. 5, 51-57.

Peters M. (1986) Autism as impairment in the formation and use of meaning: an attempt to integrate a functional and neuronal model. $J$. Psychol. 120, 69-81.

Prior M. R. (1979) Cognitive abilities and disabilities in infantile autism: a review. $J$. abnorm. child Psychol. 7, 357-380.

Prior M. R. (1987) Biological and neuropsychological approaches to childhood autism. Br. J. Psychiat. 150, 8-17.

Prior M. R., Gazjago C. C. and Knox D. T. (1976) An epidemiological study of autistic and psychotic children in the 4 eastern states of Australia. Aust. N.Z. J. Psychiat. 10, 173184.

Ricks D. M. and Wing L. (1975) Language, communication, and the use of symbols in normal and autistic children. J. Autism child Schizophrenia 5, 191-222.

Rimland B. (1964) Infantile Autism. AppletonCentury-Crofts, New York.

Ritvo E. R., Cantwell D., Johnson E., Clements M. C., Benbrook F., Slagel S., Kelly P. and Ritz M. (1971) Social class factors in autism. J. Autism child. Schizophrenia 1, 297-310.

Ritvo E. R., Jorde L. B., Mason-Brothers A., Freeman B. J., Pingree C., Jones M. B., McMahon W. M., Peterson P. B., Jenson W. R. and Mo A. (1989) The UCLA-University of Utah epidemiological survey of autism: Recurrence risk estimates and genetic counselling. Am. J. Psychiat.146, 1032-1036.

Runco M. A., Charlop M. and Schreibman L. (1986) The occurence of autistic childrens' self-stimulation as a function of familiar versus unfamiliar stimulus conditions. $J$. Autism dev. Disorders 16, 31-44.

Rutter M. and Lockyer L. (1967) A five to fifteen year follow-up of infantile psychosis: I. Description of sample. Br. J. Psychiat. 113, 1169-1182.

Rutter M. and Schopler E. (1987) Autism and pervasive developmental disorders: Concepts and diagnostic issues. J. Autism dev.

Disorders 17, 159-186.
Sanua V. D. (1986, August) Socioeconomic status and intelligence of parents of autistic children. Paper presented at the third world congress of infant psychiatry and allied disciplines, Stockholm, Sweden.

Sanua V. D. (1987) Infantile autism and parental socioeconomic status: A case of bimodal distribution. Child Psychiat. human Dev. 17, 189-198.

Schopler E., Andrews E. C. and Strupp K. (1979) Do autistic children come from upper-middle class parents? J. Autism dev. Disorders. 9, 139-152.

Shucard D. W. and Horn J. L. (1972) Evoked cortical potentials and measurement of human abilities. J. comp. physiol. Psychol. 78, 59-68.

Sigman M., Ungerer J. A., Mundy P. and Sherman T. (1987) Cognition in autistic children. In Handbook of Autism (Edited by Cohen D. J. and Donellan A. M.). Wiley, New York.

Silberberg N. E. and Silberberg M. C. (1967) Hyperlexia: specific word recognition skills in young children. Exceptional Child. 34, 41-42.

Smalley S. L., Asarnov R. F. and Spence M. A. (1988) Autism and genetics. Archs gen. Psychiat. 45, 953-961.

Snowling M. and Frith U. (1986) Comprehension in 'hyperlexic' readers. J. exp. child Psychol. 42, 392-415.

Sofaer J. and Emery A. E. (1981) Genes for super-intelligence. J. med.Genet. 18, 410-413.

Treffert D. A. (1970) Epidemiology of infantile autism. Archs gen. Psychiat. 22, 431-438.

Tsai L., Stewart M. A., Faust M. and Shook S. (1982) Social class distribution of fathers of children enrolled in Iowa program. J. Autism dev. Disorders 12, 211-221.

Volkmar F. R. (1987) Social development. In Handbook of Autism (Edited by Cohen D. J. and Donellan A. M.)). Wiley, New York.

Walker H. A. (1976) The incidence of minor physical anomalies in autistic patients. In The Autistic Syndromes (Edited by Coleman M.). North-Holland, Amsterdam.

Walker H. A. and Coleman M. (1976) Characteristics of adventitious movements in autistic children. In The Autistic Syndromes (Edited by Coleman M.). North-Holland, Amsterdam.

Ward T. F. and Hoddinott B. A. (1965) A study of childhood schizophrenia and early infantile autism. Can. Psychiat. Ass. J. 10, 377-386. 
Watson J. D., Hopkins N. H., Roberts J. W., Steitz J.A. and Weiner A. M. (1987)

Molecular Biology of the Gene (4th edition)

Benjamin/Cummings, Menlo Park, CA.

Welsh M., Pennington B. and Rogers S. (1987)

Word recognition and comprehension skills in hyperlexic children. Brain Language 32, 7696.

Wiedel L. and Coleman M. (1976) The autistic and control population of this study. In The Autistic Syndromes (Edited by Coleman M.). North-Holland, Amsterdam.

Wilson E. O. (1978) On Human Nature. Harvard University Press, Cambridge, MA.

Wing L. (1976) Diagnosis and definition. In Early Childhood Autism (2nd edition) (Edited by Wing L.). Pergamon, Oxford.

Wing L. (1980) Childhood autism and social class: A question of selection? Br. J. Psychiat. 137, 410-417.

Wing, L (1988) The autistic continuum. In Aspects of Autism (Edited by Wing L.). Gaskell, London.

Wing L., and Gould J. (1979) Severe impairments of social interaction and associated abnormalities in children: Epidemiology and classification. J. Autism dev. Disorders 9, 11-29.

Wing L. and Wing J. K. (1971) Multiple impairments in early childhood autism. $J$. Autism child Schizophrenia 1, 256-266. 